\title{
MANAJEMEN TERMINASI UMAR BIN KHATTAB DALAM KASUS PEMBERHENTIAN KHALID BIN WALID
}

\author{
Andi Susanto \\ STID Al-Hadid, Surabaya \\ andisusanto@stidalhadid.ac.id
}

\begin{abstract}
Abstrak: Artikel ini berangkat dari permasalahan terminasi SDM, yang mengakibatkan gejolak dalam organisasi dan berpotensi memecah belah kekuatan organisasi sehingga tidak bisa mencapai tujuan organisasi. Hal ini, khususnya pada SDM yang memilki peran besar dalam berkembangnya organisasi dakwah atau organisasi dengan misi dakwah. Artikel ini, mengangkat manajemen terminasi yang dilakukan oleh Umar bin Khattab dalam kasus terminasi Khalid bin Walid sebagai SDM. Artikel ini, menggunakan pendekatan teori Good Endings: Managing Employee Terminations, dan menggunakan pendekatan metode kualitatif library research. Hasil dari studi ini menunjukkan (1) Umar bin Khattab melakukan manajemen terminasi dengan mengembangkan pedoman temu duga pemutusan hubungan kerja dengan Khalid bin Walid, (2) Umar bin Khattab melakukan terminasi kepada Khalid bin Walid dengan mempertimbangkan penyampai terminasi yang tepat, perihal terminasi sesuai pedoman yang sudah dibuat, momen penyampaian terminasi yang sesuai dengan konteks masalah, tempat disampaikannya terminasi yang bisa netral diterima, penyampaian alasan yang logis terminasi yang bisa diterima, dan cara penyampaian terminasi yang bisa diterima.

Kata kunci: Manajemen terminasi SDM, Umar bin Khattab, pemberhentian Khalid bin Walid
\end{abstract}

Umar Bin Khattab's Termination Management - The Dismissal Case of Khalid Bin Walid. Abstract: The study is grounded in a case of terminating a human resource, causing organizational turmoil and potentially divide the organizational strength so that they cannot achieve its goals. It especially happens when the human resource has a big role in the development of da'wah organization. This article reveals the termination management carried out by Umar bin Khattab in the dismissal case of Khalid bin Walid as his human resource. It uses a theoritical approach of Good Endings: Managing Employee Termination and a qualitative library research method approach. It indicates that (1) Umar bin Khattab carried out a termination management by developing a question and answer guideline for terminating Khalid bin Walid; (2) Umar bin Khattab terminated Khalid bin Walid by considering for the right person to deliver the termination news, the matter of termination related to the guideline made, the moment for delivering termination which was suitable to the problem context, the place where the termination delivery place which was fairly accepted, accepted logical reasoning of termination and the way of termination delivery which was accepted.

Key words: Human Resource Termination Management, Umar bin Khattab, dismissal case of Khalid bin Walid 


\section{Pendahuluan}

Sutrisno dalam Maringka, ${ }^{1}$ sumber daya manusia (SDM) adalah aset dari perusahaan atau organisasi yang memiliki kontribusi demi tercapainya tujuan perusahaan atau organisasi tersebut. Kompetensi mereka berperan penting dalam pencapaian keuntungan yang dicapai oleh perusahaan atau organisasi. Manajemen sumber daya manusia menurut Sedamayanti dalam Winarti, ${ }^{2}$ mulai dari tahapan perencanaan ketenagakerjaan, sampai pemensiunan/terminasi pegawai. Maka dibutuhkan manajemen sumber daya manusia (MSDM) oleh manajer perusahaan atau organisasi dalam mengelola sumber daya manusia dengan baik agar tujuan dari perusaahaan atau organisasi bisa tercapai dengan baik.

Manajemen sumber daya manusia sesuai dengan hadist Nabi yaitu: Rasulullah saw., bersabda: "apabila amanah telah dicabut maka tunggulah kehancuran (kiamat)", Abu Hurairah bertanya "bagaimana dicabutnya amanah ya Rasulullah?" Nabi menjawab: "apabila sesuatu telah diserahkan kepada yang bukan ahlinya maka tunggulah kehancuran." Dengan demikian tujuan

\footnotetext{
1. Inggrit Natalia Maringka, Lotje Kawet, Irvan Trang, "Hubungan Lingkungan kerja dan kompensasi terhadap kinerja karyawan pada PT. Bank SULUTGO Cabang Utama Manado", Jurnal EMBA vol. 5, No. 2 (Juni 2017):2251-2259, doi https://doi.org/10.35794/emba.v5i2.16653

2. Endah Winarti, "Perencanaan Manajemen Sumber Daya Manusia Lembaga Pendidikan", Jurnal Tarbiyatuna vol. 3, no. 1 (2018): 1-26, http://ejournal.kopertais4.or.id/mataraman/index.ph $\mathrm{p} /$ tarbiyatuna/article/download/3434/2577/

3. Muhammad bin Ismail Abu Abdillah Al-BukharyalJa'fi, al-Jami al-Shahih al-Muhtashar, Jilid I, (Beirut: Dar ibn Katsir, 1987/1407), 33.

4. Mawey Z. Alfa, Sri Murni, Ferdy Roring, "Faktor-faktor yang mempengaruhi Pemutusan Hubungan Kerja Karyawan Pada PT. PLN (Persero) Rayon Manado Utara", Jurnal EMBA vol. 4, no. 1 (Maret 2016): 261271, doi: https://doi.org/10.35794/emba.v4i1.11594
}

manajemen sumber daya manusia adalah menempatkan SDM yang ahli dalam suatu pekerjaan, dan memberhentikan SDM jika dirasa tidak ahli, dikarenakan bisa menyebabkan kehancuran. ${ }^{3}$

Salah satunya, dalam dinamika manajemen sumber daya manusia adalah pemberhentian SDM, atau disebut dengan terminasi. Menurut Kuncoro dalam Alfa, Murni dan Roring, ${ }^{4}$ pemberhentian kerja didefinisikan sebagai berhentinya hubungan kerja secara permanen antara perusahaan dengan karyawannya, dengan berbagai alasan. Salah satu alasan yang bisa diterima dalam proses pemberhentian pegawai adalah berupa kesalahan serius dari pegawai yang menyebabkan tidak tercapainya tujuan dari organisasi. ${ }^{5}$ Menurut Prameswari dan Handayani, ${ }^{6}$ manajemen terminasi perlu dilakukan agar bisa menentukan langkah yang "paling tidak pahit" bagi kedua belah pihak, dengan demikian bisa meminimalisir dampak bagi perusahaan atau organisasi yang melakukan terminasi.

Namun kenyataannya, terdapat permasalahan yaitu manajemen terminasi pengurus dari organisasi dakwah. Mengutip berita, ${ }^{7}$ salah satunya pemberhentian salah

5. Robert A. Finnie, JR dan Paul B. Sniffin, Good Endings: Managing Employee Terminations, (Washington: College and University Personnel Associations, 1984), 9.

6. Karina Prameswari dan Emi Puasa Handayani, "Pengaturan Pemutusan Hubungan Kerja Antara Karyawan Dengan Perusahaan", Mizan: Jurnal Ilmu Hukum vol. 8, no. 1 (Juni 2018): 99-112. https://ejournal.uniskakediri.ac.id/index.php/Mizan/article/view/923/7 34

7. Huzair Zainal, "Kisruh Lebaran Lebih Awal, Imam Masjid Dipecat", Okenews.com, 2 September 2011 https://news.okezone.com/read/2011/09/02/34 0/498279/kisruh-lebaran-lebih-awal-imammasjid-dipecat. (diakses tanggal 9 November, 2020) 
satu pengurus di kepengurusan masjid menimbulkan ketegangan dan kekisruhan dalam organisasi dakwah pasca pemberhentian, bagi yang pendukung pengurus yang dipecat menyatakan pemberhentian dianggap semena-mena. Pernyataan tersebut dikarenakan pengurus masjid yang tidak mendapatkan pemberitahuan, langsung diberhentikan oleh pihak yang berwenang melakukan pemberhentian dan tidak melakukan dialog dengan pengurus yang diberhentikan.

Terlepas mengenai benar dan salah alasan pemberhentian SDM organisasi dakwah, manajemen terminasi yang dilakukan oleh suatu organisasi terhadap SDM-nya mengalami perlawanan dan berujung pada gejolak di dalam internal organisasi tersebut. Terlihat dari manajemen pemberhentian (terminasi) khususnya dalam tahapan penyampaian saat terminasi pihak berwenang memberhentikan terhadap SDM tidak berjalan dengan baik, yang menyebabkan ketidakstabilan dalam internal organisasi masjid.

Hal ini, berbeda dengan yang dilakukan oleh Umar bin Khattab, Umar melakukan terminasi kepada salah satu panglima besar Islam Khalid bin Walid yang merupakan salah satu panglima muslim yang pada saat itu sangat disegani oleh semua pasukan

8. Muhammad Husain Haekal. Umar bin Khattab, penerjemah: Ali Audah. (Jakarta: PT Pustaka Litera antarNusa, 2013), 309.

9. Saifullah yang memiliki arti dalam Bahasa Indonesia adalah Pedang Allah, dan ini adalah suatu gelar, serta gelar ini diberikan oleh Rasulullah kepada Khalid bin Walid, mengutip Shadiq Ibrahim Argoun, Rasulullah saw., pun menggelari Khalid dengan Saifullah (pedang Allah), Turmudzi meriwayatkan dari Abu Hurairah r.a, ia berkata "Kami singgah di suatu tempat bersama Rasulullah, semua orang berjalan melewati beliau. Rasulullah lantas menanyakan muslimin untuk menegakkan kalimat tauhid dalam memenangkan peperangan di daerah Irak sampai Syam, ${ }^{8}$ Khalid bin Walid Sang Saifullah. ${ }^{9}$

Umar melakukan manajemen terminasi terhadap pemberhentian Khalid bin Walid dalam kasus tersebut salah satunya dengan mendelegasikan tugas pemecatan kepada SDM yaitu Abu Ubaidah, dan dalam pemberhentian tersebut muncul gejolak dalam diri Khalid, dan dalam proses manajemen terminasi yang dilakukan oleh Umar, akhirnya gejolak dari diri Khalid bisa meredam dan menerima hasil dari pemberhentian dirinya dengan melakukan serangkaian langkah-langkah manajemen terminasi, Khalid dengan keimanan Islam yang kuat di dada berkata "Selama Umar masih hidup, tidak" menolak ajakan memberontak kepada Umar atas pemberhentian dirinya. ${ }^{10}$

Umar bin Khattab mampu melakukan langkah-langkah manajemen terminasi yang tidak berlarut-larut dan stabilitas organisasi bisa terjaga dalam mencapai tujuan organisasi, dengan meredam gejolak dalam diri Khalid selama proses terminasi dan meredam segala gejolak umat Islam saat itu. Artikel ini, berangkat dari peristiwa manajemen terminasi yang dilakukan oleh Umar bin Khattab dalam pemberhentian

siapa mereka masing-masing. Beliau bersabda, "Siapa orang itu?" Aku menjawab, "Fulan," Sampai kemudian Khalid bin Walid berjalan melewati beliau. Kemudian Rasulullah saw., bertanya, "Siapa orang itu?" Aku menjawab, "Khalid bin Walid." Kemudian, beliau bersabda, "Sebaik-baik hamba Allah adalah orang itu. Ia Adalah Salah satu pedang Allah." Dalam dalam Shadiq Ibrahim Argoun, Khalid Bin Walid Sang Legenda Militer Islam, (Tinta Medina: Solo, 2015), 68.

10. Muhammad Husain Haekal, Umar bin Khattab, 320. 
Khalid bin Walid dalam pekerjaan di kekhalifahan. Maka, demikian fokus masalah studi ini adalah bagaimana manajemen terminasi Umar bin Khattab dalam kasus pemberhentian Khalid bin Walid. Tujuan artikel ini adalah untuk menganalisis manajemen terminasi Umar bin Khattab dalam kasus pemberhentian Khalid bin Walid.

Kontribusi bagi perkembangan manajemen dakwah, yaitu menjadi sumber referensi manajemen terminasi yang dilakukan oleh manajer terhadap SDM organisasi dakwah di masa kini, langkah-langkah apa saja yang bisa dilakukan untuk bisa mencapai tujuan terminasi yang baik yaitu SDM menerima pemberhentian atas dirinya dan tidak menimbulkan gejolak dalam organisasi dakwah kedepan. Dengan begitu manajer bisa fokus pekerjaan yang selainnya pasca terminasi SDM tersebut.

Artikel-artikel sebelumnya yang membahas terkait terminasi Khalid bin Walid oleh Umar bin Khattab, antara lain, pertama, artikel jurnal "Peran Umar Bin Khattab dalam Manajemen Konflik", ${ }^{11}$ artikel ini bertujuan menggambarkan manajemen konflik salah satunya adalah adanya konflik di dalam pemberhentian Khalid bin Walid oleh Umar bin Khattab dan bagaimana Umar melakukan menajemen konflik di dalam situasi tersebut. Artikel tersebut dengan artikel ini sama-sama menjelaskan mengenai pemberhentian Khalid bin Walid oleh Umar bin Khattab, tetapi perbedaanya dalam

11. Agni Miranti, Yuana Tri Utomo, dan Wijiharta, "Peran Umar Bin Khattab dalam Manajemen Konflik", AT-TAUZI': Jurnal Ekonomi Islam vol. 16, no. 1 (2017), 95 - 109, http://jurnalhamfara.ac.id/index.php/attauzi/art icle/view/28 perspektif. Dalam studi ini berdasarkan manajemen sumber daya manusia spesifiknya adalah manajemen terminasi (pemberhentian), sedangkan artikel tersebut menjelaskan lewat perspektif manajemen konflik.

Artikel kedua, jurnal "The Appointment and Dismissal of Khalid B. Al Walid Form the Supreme Command A Study of The Political Strategy of The Early Muslim Caliphs in Syria", ${ }^{12}$ artikel ini bertujuan menggambarkan analisa-analisa sejarah alasan yang menjadi penyebab diberhentikannya Khalid bin Walid dari dinas kemiliteran oleh Umar bin Khattab dalam sudut pandang strategi politik. Artikel tersebut dengan artikel ini sama-sama membahas alasan pemberhentian, tetapi perbedaanya dalam subyek penelitian. Dalam studi ini membahas mengenai manajemen terminasi (pembehentian) dari sudut pandang teori manajemen terminasi Finnie dan Sniffin, sedangkan artikel tersebut lebih mendeskripsikan analisa sejarah alasan Khalid diberhentikan dalam dinas kemiliteran oleh Umar bin Khattab.

Signifikansi artikel ini secara keseluruhan adalah melengkapi perspektif peristiwa terminasi/pemberhentian Khalid bin Walid oleh Umar bin Khattab, sesuai dengan perspektif manajemen sumber daya manusia khususnya dalam manajemen terminasi sehingga bisa melihat perspektif manajemen terminasi yang mampu menghindari permasalahan yang berlarut-

12. Khalil Athamina, The Appointment and Dismissal of Khalid B. Al Walid Form the Supreme Command A Study of The Political Strategy of The Early Muslim Caliphs in Syria, Arabica E.J Brill Leiden, Tome XLI (1994): 253-272, doi: https://doi.org/10.1163/157005894X00191 
larut yang mengakibatkan kerugian waktu, tenaga pikiran dan materi.

Artikel ini menggunakan metode library research, dengan subjek artikel manajemen terminasi dan objek artikel peritiwa pemberhentian Khalid bin Walid oleh Umar bin Khattab. Sumber primer yang digunakan adalah buku Umar bin Khattab karya Muhammad Husein Haekal, Khalid bin Walid Penglima Tak Terkalahkan karya Manshur Abdul Hakim, Khalid Bin Walid Sang Legenda Militer Islam karya Shadiq Ibrahim Argoun, Biografi Umar bin Khattab karya Ali Muhammad Ash-Shalaby dan artikel The Appointment and Dismissal of Khalid B. Al Walid Form the Supreme Command A Study of The Political Strategy of The Early Muslim Caliphs in Syria, karya Khalil Athamina. Sumber sekunder/ penunjang adalah bukubuku dan artikel jurnal terkait yang membahas masalah terminasi/ pemberhentian Khalid bin Walid oleh Umar bin Khattab. Menurut Huberman dan Miles, ${ }^{13}$ analisis data dilakukan secara kualitatif mengikuti model Miles dan Huberman yaitu mulai reduksi data (pemilahan data), penyajian data, dan penarikan kesimpulan.

\section{Manajemen Terminasi}

13. Ismail Nawawi, Metode Penelitian Kualitatif, (Jakarta: Dwiputra Pustaka Jaya, 2012), 256-259.

14. M. Nazar Almasri, "Manajemen Sumber Daya Manusia: Implimentasi Dalam Pendidikan Islam", Kutubkhanah: Jurnal Penelitian Sosial Keagamaan vol. 19, no. 2 (Jul-Des 2016): 133150, $\quad$ http://ejournal.uinsuska.ac.id/index.php/Kutubkhanah/article/view $\lcm{2547}$

15. Herly Dwiyanto, “Manajemen Sumber Daya Manusia Madani di Universitas Negeri", Jurnal
Manajemen sumber daya manusia merupakan pengaturan dan pengelolaan terhadap sumber daya manusia. Menurut Edwin Flippo yang dialih bahasakan oleh Moh. Masud dalam Almasri, ${ }^{14}$ manajemen sumber daya manusia adalah perencanaan, pengorganisasian, pengarahan, dan pengendalian atas pengadaan tenaga kerja, pengembangan, kompensasi, integrasi, pemeliharaan, dan pemutusan hubungan kerja dengan sumber daya manusia untuk mencapai sasaran perorangan, organisasi, dan masyarakat.

Proses manajemen SDM terbagi ke dalam 2 (dua) fungsi, yakni fungsi manajerial dan fungsi operasional. Fungsi manajerial dalam manajemen SDM meliputi planning atau perencanaan, organizing atau pengorganisasian, directing atau pengarahan, dan controlling atau Pengendalian. Sementara itu, yang termasuk dalam fungsi operasional manajemen SDM adalah pengadaan tenaga kerja/karyawan, pengembangan, pengintegrasian, pemeliharaan, kompensasi, dan pemutusan hubungan kerja (PHK). ${ }^{15}$

Menurut Sonhaji, ${ }^{16}$ terminasi adalah sanksi pelanggaran bagi pekerja/buruh yang paling berat dalam hubungan kerja yang mengakibatkan berakhirnya hak dan

Prodi Manajemen Pertahanan vol. 3, no. 2 (2017):

61-72, http://jurnalprodi.idu.ac.id/index.php/MP/articl e/view/178

16. Sonhaji, "Analisis Yuridis Pemutusan Hubungan Kerja Akibat Kesalahan Berat Pekerja", Administrative Law \& Governance Journal vol. 2, no.1 (Maret 2019): 60-78, doi: https://doi.org/10.14710/alj.v2i1.60-78 
kewajiban antara pengusaha dan pekerja/buruh.

Manajemen terminasi merupakan bagian dari manajemen sumber daya manusia guna melaksanakan salah satu fungsi operasional dari manajemen SDM. Pengertian manajemen terminasi sendiri adalah kegiatan perencanaan, pengorganisasian, pengarahan, dan pengendalian atas pemutusan hubungan kerja yang dilakukan oleh manajer. Manajemen terminasi muncul ketika pekerja melakukan pelanggaran dan diberikan sanksi berat berupa terminasi, maka manajer melakukan proses perencanaan, pengorganisasian, pengarahan, dan pengendalian agar proses terminasi tersebut bisa mencapai mencapai tujuan organisasi.

Mengutip Prameswari dan Handayani, ${ }^{17}$ manajemen terminasi dilakukan guna menentukan langkah yang "paling tidak pahit" bagi kedua belah pihak, dengan demikian bisa meminimalisir dampak bagi perusahaan atau organisasi yang melakukan terminasi.
17. Prameswari dan Handayani, "Pengaturan Pemutusan Hubungan Kerja Antara Karyawan Dengan Perusahaan", https://ejournal.uniskakediri.ac.id/index.php/Mizan/article/view/923/7 $\underline{34}$

18. Indi Nuroini, "Penerapan Perjanjian Bersama Dalam Pemutusan Hubungan Kerja", Jurnal Yudisial vol. 8, no. 3 (2015): 319-338, doi: http://dx.doi.org/10.29123/iy.v8i3.61

19. Ahmad Zaini, "Pengaturan Pemutusan Hubungan Kerja (PHK) Menurut Peraturan Perundangan-undangan Ketenagakerjaan", AlAhkam vol. 13, no. 1 (Juni 2017): 76-110, doi: http://dx.doi.org/10.37035/ajh.v13i1.1753

\section{Macam- Macam Pemutusan Hubungan Kerja}

Diberhentikannya hubungan antara pekerja dan organisasi dalam hubungan kerja, bisa dilakukan dengan sukarela dan tidak. ${ }^{18}$ Menurut Sutedi dalam Zaini, ${ }^{19}$ diperkuat oleh Buwana dan Putra, ${ }^{20}$ pemutusan/terminasi/pemberhentian bisa dilakukan disebabkan adanya maksud dari perusahaan atau organisasi, bisa juga dari pekerja yang berdasarkan keinginannya ataupun adanya alasan lain yang menyebabkan hubungan kerja tersebut harus diputus. Dalam hal ini, jika pekerja tersebut memutuskan hubungan kerja sendiri, maka disana ada niatan yang berasal dari diri pekerja tersebut untuk berhenti, di sini menandakan adanya keikhlasan dalam proses tersebut, tetapi jika bukan berasal dari pekerja itu sendiri, bisa menimbulkan rasa ketidakrelaan dari pekerja tersebut.

Dalam Muslim, ${ }^{21}$ bekerja bagi seseorang yang diberhentikan, dapat dikatakan bahwa kehilangan pekerjaan atau pemberhentian merupakan satu peristiwa yang menjadi sumber stres yang mempengaruhi emosi seseorang karena dengan kehilangan pekerjaan, individu tidak lagi memiliki kesempatan untuk mengekspresikan diri dan kehilangan kesempatan untuk

${ }^{20}$. Sudibyo Aji Narendra Buwana dan Mario Septian Adi Putra, "Implimentasi Pemutusan Hubungan Kerja (PHK) Terhadap Pekerja Status Perjanjian Kerja Waktu Tertentu (PKWT) Pada PT $X$ Kota Malang", Jurnal Studi Manajemen vol. 9, no. 2 (Okt 2015): 202-214, https://ecoentrepreneur.trunojoyo.ac.id/kompetensi/article /view/1628

21. Muh. Muslim, "Dilema Pemutusan Hubungan Kerja Bagi Karyawan", ESENSI: Jurnal Manajemen Bisnis vol. 18, no. 3 (2015): 100-110, https://ibn.ejournal.id/index.php/ESENSI/article/view/100 
mengembangkan kemampuan yang dimiliki. Oleh karena itu, manajer bisa melakukan manajemen terminasi dengan tepat agar pekerja tidak berlarut-larut dalam emosi kehilangan pekerjaan dan merugikan organisasi kedepannya, dengan melakukan penyampaian pesan terminasi secara singkat, manusiawi, dan final.

Menurut Widayanti, ${ }^{22}$ pemberhentian seringkali menimbulkan ketidakpuasan bagi salah satu pihak dikarenakan masing-masing pihak memiliki sudut pandang berbeda menyikapi pemberhentian. Mengutip Swasto, ${ }^{23}$ Fathammubina dan Apriani, ${ }^{24}$ macam-macam bentuk pemutusan hubungan kerja yang membuat pekerja tidak rela yaitu: (1) Pensiun, dikarenakan SDM mencapai batas usia tertinggi maka dilakukan pemutusan hubungan kerja. Dengan begitu, pekerja atau SDM, mau tidak mau harus berhenti dari pekerjaannya; (2) Pemecatan, ketika SDM melakukan kesalahan dan dianggap fatal dalam pencapaian tujuan organisasi, maka dilakukan pemecatan terhadap pekerja tersebut. Terminasi di sini adalah langkah penghentian hubungan kerja antara organisasi dengan SDM yang di sini sama dengan pemecatan atau pemberhentian SDM atas segala pekerjaan serta jabatan yang diemban, SDM tersebut diberhentikan dikarenakan organisasi mengambil keputusan atas dasar tertentu; (3) Pengurangan tenaga, ketika organisasi sedang mengalami kerugian dan

\footnotetext{
22. Widayanti, "Tinjauan Pelaksanaan Pemutusan Hubungan Kerja (PHK) Berdasarkan Undangundang Nomor 13 Tahun 2003 Tentang Ketenagakerjaan", Hukum dan Dinamika Masyarakat vol. 15, no. 2 (April 2018): 168-176, doi: http://dx.doi.org/10.36356/hdm.v15i2.686 23. Bambang Swasto, Manajemen Sumber Daya Manusia, (Malang: UB Press, 2011), 130.
}

dilakukannya pengurangan tenaga kerja untuk efisiensi, maka di sini akan ada pemutusan hubungan kerja, dan di sini mau tidak mau dan membuat ketidakrelaan dari pekerja yang diberhentikan;

Pembubaran organisasi, ketika organisasi dibubarkan maka di sini akan ada pemaksaan terhadap pekerja untuk keluar; (4) Pemutusan hubungan kerja sementara, ketika pekerjaan yang tersedia musiman, maka ketika tidak musimnya, maka akan ada pemutusan hubungan kerja terhadap pekerja, dan ketika pekerjaan tersebut masuk musimnya, maka akan dipekerjakan kembali.

Dengan adanya pemberhentian dengan segala macam bentuknya seperti yang disebutkan diatas, pemberhentian ini dilakukan dengan paksa kepada pekerja, maka di sini akan menimbulkan gejolak dalam upaya pemberhentiannya, dikarenakan sumber financial, lahan berkarya dalam pekerjaan tersebut hilang bagi pekerja yang diberhentikan, padahal pekerjaan selama ini dilakukan untuk memenuhi kebutuhan materiil dan batin dari pekerja, terlebih ketika pekerja tersebut menemukan kebermaknaan dalam pekerjaannya selama ini dan tidak bisa ikut terlibat dalam pencapaian tujuan organisasi tersebut.

Menurut Robert A. Finnie, JR dan Paul B. Sniffin, ${ }^{25}$ terminasi yang baik tidak akan menjadi pengalaman yang mahal dan tidak

\footnotetext{
24. Rohendra Fathammubina, Rani Apriani, "Perlindungan Hukum Terhadap Pemutusan Hubungan Kerja Sepihak bagi Pekerja", Jurnal Ilmiah Hukum De'Jure: Kajian IImiah Hukum vol. 3, no. 1 (Mei 2018): 108-130, doi: https://doi.org/10.35706/dejure.v3i1.1889 25 Robert A. Finnie. JR, Paul B. Sniffin, Good Endings: Managing Employee Terminations,
} 
menyenangkan bagi anda dan organisasi anda, serta individu yang pergi.

Mengutip Robert A. Finnie, JR dan Paul B. Sniffin, ${ }^{26}$ oleh sebab itu seorang manajer atau pimpinan organisasi bisa melakukan langkah manajemen terminasi yang baik agar tidak menghasilkan pengalaman yang mahal dan tidak menyenangkan bagi pekerja dan tidak menimbulkan gejolak, tanpa rasa sakit, untuk mencapai tujuan itu seorang manajer dalam melakukan manajemen terminasi bisa melakukan tahapan dalam pemberhentian:

\section{Tahapan sebelum terminasi}

Tahapan sebelum terminasi, merupakan tahapan yang dilakukan oleh manajer personalia sebelum melakukan tahapan saat terminasi/pemberhentian kepada SDM yang telah diputuskan untuk diberhentikan, yang tahapan saat terminasi berisi penyampaian keputusan terminasi kepada SDM. Tujuan tahapan ini dilakukan agar manajer personalia sebelum melakukan penyampaian terminasi/pemberhentian kepada SDM, bisa diberikan masukan opsiopsi cara penyampaian terminasi kepada SDM, dengan begitu manajer personalia bisa memilih pilihan terbaik dan pilihan penyampaian tersebut bisa meminimalisir dampak negative bagi organisasi.

Langkah pertama sebelum masuk ke dinamika saat terminasi, dalam pendekatan ini, langkah yang dilakukan adalah: (1) Merencanakan terminasi, setelah keputusan untuk menterminasi dibuat, rapat tim pemutusan hubungan kerja diadakan untuk mengembangkan pedoman khusus tentang

(Washington DC: College and Univ. Personnel Association, 1984), 9. bagaimana melakukan temu duga/tanya jawab pemutusan hubungan kerja, topik yang akan dibahas meliputi, mulai bantuan yang akan diberikan setelah pemutusan hubungan kerja, kelanjutan tunjangan karyawan, dan informasi latar belakang orang yang dipecat, termasuk faktor-faktor khusus seperti masalah keluarga atau kesehatan, atau kondisi lain yang dapat memperburuk terminasi; (2) Yakinkan manajemen senior jika ada, dengan mengkomunikasikan keseriusan situasi yang terjadi, rapat dengan pihak-pihak yang memiliki kepentingan, ketemu dengan pembuat keputusan lainnya dan dengarkan pendapat mereka untuk bisa menyusun komunikasi yang tepat saat terminasi; (3) Komunikasikan kepada kolega dan staff, komunikasikan pendekatan terminasi yang manajer buat kepada kolega dan staff yang tertarik dalam tema terminasi tersebut, agar bisa mendapatkan opsi-opsi yang bisa dilakukan saat terminasi dan bisa meminimalisir dampak negatif bagi organisasi.

\section{Tahapan saat terminasi}

Dalam tahapan saat terminasi, merupakan proses dalam pertemuan antara manajer personalia/pihak yang berwenang memberhentikan untuk penyampaian terminasi dengan pekerja, dan dalam pertemuan tersebut merupakan hal yang tidak disangka oleh pekerja. Di dalam organisasi tidak semua jajaran manajemen bisa mengkomunikasikan dalam pertemuan tersebut dengan baik, maka manajer harus bisa menyampaikan pesan dengan cara yang singkat, manusiawi, dan final. Untuk bisa mengkomunikasikan terminasi kepada

${ }^{26}$ Ibid., $13-16$ 
pekerja agar bisa mengindari trauma pekerja yang diterminasi.

Di bawah ini terdapat standar menurut Finnie dan Sniffin, ${ }^{27}$ mengkomunikasikan terminasi tersebut agar terminasi tersebut bisa memenuhi kelogisan, sensitifitas, singkat, manusiawi, dan final bagi pekerja tersebut, yaitu: (1) "Siapa" yang akan menyampaikan, bisa seseorang yang dianggap senior atau dihormati untuk disampaikannya terminasi tersebut; (2) "Apa" kata-kata yang disampaikan kepada pekerja yang akan dipecat harus menunjukkan rasa hormat, bisa juga dengan bahasa non-verbal menunjukkan rasa hormat tersebut; (3) "Kapan" waktu yang tepat untuk menyampaikan pesan terminasi tersebut, dimana situasi yang bisa diterima dan momen yang tepat dalam pencapaian tujuan organisasi; (4) "Dimana" tempat disampaikannya pesan/hasil keputusan terminasi tersebut, bisa ditempat netral atau tempat yang mendukung penyampaian pesan/hasil keputusan; (5) "Mengapa" pekerja tersebut diterminasi, yaitu berupa alasan yang terbaik bagi organisasi dan pekerja itu sendiri dalam pesan/hasil keputusan terminasi dirinya; (6) "Bagaimana" pesan tersebut disampaikan, yaitu dengan bersikaplah positif, menenangkan, dan tegas agar situasi bisa sesuai dengan harapan, dan tunjukkan pertimbangan dan perhatian, tetapi pastikan

27. Ibid.

28. Husaini, Happy Fitria, "Manajemen Kepemimpinan Pada Lembaga Pendidikan Islam", Jurnal Manajemen, Kepemimpinan, dan Supervisi Pendidikan vol. 4, no. 1, (Januari-Juni 2019): 4354 , doi: http://dx.doi.org/10.31851/jmksp.v4i1.2474

29. Rahmat llyas, "Manusia sebagai Khalifah dalam perfektif Islam", Mawa izh vol. 1, no. 7 (Juni finalitas pesan/hasil keputusan terminasi tersebut jelas.

Sejalan dengan pendapat Ramayulis dalam Husaini dan Happy Fitria menyatakan, ${ }^{28}$ manusia yang diciptakan Allah Swt. Telah dijadikan sebagai khalifah di bumi sebagai wakil Allah Swt. Untuk melakukan mengatur dan mengelola bumi dengan sebaik-baiknya sebagaimana Allah Swt. Sebagai pengatur alam raya (manager). Salah satu perannya adalah jihad di jalan Allah. ${ }^{29}$

Jihad disyariatkan dengan peperangan. Tujuan berjihad dalam Islam, Nabi saw., dan para pengikutnya harus berjihad hingga terbuka jalan dakwah agar manusia dapat sampai kepada kemudahan dan tanpa rintangan. Motif jihad membuka jalan dakwah yaitu (1) Melindungi kebebasan dalam beragama, (2) Melindungi kebebasan dalam beragama, (3) Berperang untuk mencegah kezaliman. ${ }^{30}$

Konsekuensi dari peran sebagai Khalifah adalah memanajemen sumber daya manusia (SDM) untuk ikut memakmurkan bumi dalam lingkup pengabdian kepada Tuhan dengan memanfaatkan seoptimal mungkin potensi yang telah dianugerahkan oleh Tuhan. Dalam Islam, pengelolaan sumber daya manusia mengacu pada apa yang dicontohkan oleh Nabi Muhammad saw., didasarkan pada konsep Islam mengenai

2016):

169-195

doi: https://doi.org/10.32923/maw.v7i1.610

30. Abdul Basith Junaidy, "Perang yang benar dalam Islam", Al-Daulah: Jurnal Hukum dan Perundangan Islam vol. 8, no. 2 (Oktober 2018): 486-512, doi: https://doi.org/10.15642/ad.2018.8.2.486-512 
manusia itu sendiri. ${ }^{31}$ Nabi melakukan manajemen SDM dalam penujukkan Mu'adz ibn Jabal sebagai gubernur, Umar ibn Khaththab sebagai bendahara negara, Khalid ibn Walid sebagai panglima perang. ${ }^{32}$ Dengan demikian dalam peperangan yang merupakan peran dari manusia sebagai Khalifah di muka bumi dibutuhkan memanajemen SDM yang baik guna melancarkan mencapai tujuan dalam perang yaitu berjihad hingga terbuka jalan dakwah secara spesifik dan melancarkan mencapai tujuan memakmurkan bumi dalam lingkup pengabdian kepada Tuhan secara umum. Menurut tafsir ar-Razi, ${ }^{33}$ terdapat tingkatan orang berjihad yaitu (1) Jihad dengan jiwanya, (2) Jihad dengan hartanya, (3) Jihad dengan niatnya.

Dengan demikian, Khalifah secara umum dan spesifik Khalifah Islam, melakukan kegiatan manajemen SDM dalam peran peperangan atau jihad. Salah satunya adalah melakukan manajemen terminasi terhadap SDM untuk menentukan orang jihad dengan jiwanya, hartanya dan niatnya.

Sejalan dengan pendapat Muslim, ketika SDM dalam pencapaian tujuan peperangan diberhentikan, SDM tersebut akan menimbulkan gejolak. Dikarenakan SDM bergabung dalam peperangan disadari bukan hanya niatan tulus untuk berperang membuka jalan dakwah demi terwujudnya tujuan khalifah di muka bumi, tetapi ada juga

31. Husaini, "Manajemen Kepemimpinan", doi: http://dx.doi.org/10.31851/jmksp.v4i1.247 $\underline{4}$

32. Sri Harmonika, "Hadist-hadits tentang Manajemen Sumber Daya Manusia (SDM)", Jurnal At-Tadair Prodi MPI STAI Darul Kalam vol.
1 ,
no.
1
(2017):1-14,

yang berdasarkan finansial yaitu mendapatkan ghanimah, dan kebutuhan batin sebagai lahan berkarya mendapatkan amal. Salah satu alasan tersebut baik motif finansial dan kepuasan batin/motif agama menjadi pemicu gejolak bagi SDM yang diterminasi. Bagi yang bermotif kepuasan batin/agama, terminasi dalam dinamika jihad merupakan sesuatu yang membawa duka, dikarenakan hilangnya lahan aktuliasasi dalam agama dan juga ladang pahala, sehingga terkadang menimbulkan gejolak ketika proses terminasinya tidak berjalan dengan baik ketika dilakukan oleh Khalifah.

Oleh karena itu, Khalifah yang melakukan terminasi, bisa melakukan manajemen dengan baik di proses terminasi SDM yang sedang berjihad. Dengan demikian, bisa memimalisir dampak gejolak yang ditimbulkan.

Untuk mencapai tujuan diatas Khalifah melakukan manajemen terminasi, sejalan dengan konsep Finnie. JR dan Sniffin, ${ }^{34}$ mulai dari tahapan sebelum terminasi dengan melakukan upaya (1) Merencanakan terminasi, dengan diskusi dengan sahabat lainnya untuk menemukan metode temu duga yang tepat untuk menyampaikan pemberhentian kepada SDM, bantuan bagi SDM yang diberhentikan dan situasi yang memperberat psikologis SDM ketika disampaikan pemberhentinnya,

http://ejournal.kopertais4.or.id/sasambo/index. php/atTadbir/article/view/2990

33. Muh. Muslim, “Dilema Pemutusan": 100-110, https://ibn.ejournal.id/index.php/ESENSI/article/view/100

34. Robert A. Finnie. JR, Paul B. Sniffin, Good Endings: Managing Employee Terminations, (Washington DC: College and Univ. Personnel Association, 1984), 13-16. 
Mengkomunikasikan dengan atasan, tidak di lakukan dikarenakan Khalifah merupakan pemimpin tertinggi, (3) Mengkomunikasikan dengan SDM yang selainnya, yang memiliki kepentingan terhadap terminasi tersebut. Tahapan ini dilakukan agar bisa mendapatkan opsi-opsi yang bisa dilakukan saat terminasi dan bisa meminimalisir dampak negatif, yaitu ketidaksesuaian terminasi pada SDM yang tidak seharusnya dan gejolak dari diri SDM yang diterminasi. Berikutnya, Khalifah dalam melakukan tahapan saat terminasi, dengan melakukan pengelolaan sumber daya saat keputusan terminasi disampaikan, agar tidak terjadi gejolak dalam diri SDM, mulai dari siapa seseorang yang dianggap senior atau dihormati untuk menyampaikan terminasi tersebut, apa kata-kata yang disampaikan kepada SDM perang yang akan dipecat harus menunjukkan rasa hormat, kapan waktu yang tepat melakukan penyampaian keputusan terminasi, dimana tempat disampaikan hasil terminasi, mengapa terminasi dilakukan kepada SDM tersebut, dan terakhir bagaimana pesan tersebut disampaikan.

\section{Umar Bin Khattab}

Umar bin Khattab adalah seorang Khalifah kedua, pengganti Rasululah setelah Abu Bakr As Siddiq. Diangkat oleh Abu Bakr As

35. Haekal, Umar bin Khattab, 79.

36. M. Al Qautsar Pratama, Budi Sujati, "Kepemimpinan dan Konsep Ketatanegaraan Umar Ibn Al-Khattab", JUSPI: Jurnal Sejarah Peradaban Islam vol. 2, no. 1 (2018): 59-70, doi: http://dx.doi.org/10.30829/i.v2i1.1496

37. Menurut Dahlan dalam Intan. Salmah Intan, "Kekhalifaan Umar Ibn Khattab (13-23 H/ 634644 M)", Rihlah: Jurnal Sejarah dan Kebudayaan vol. 5, no. 2 (2017): 137-151, http://journal.uin-
Siddiq..$^{35}$ Umar melanjutkan apa yang sudah dilakukan Abu Bakar di Irak dan Syam, Penguasaan Imperium Persia dan Imperium Romawi menjadi puncak dari keberhasilan Umar ibn al-Khattab dalam memimpin Bangsa Arab. ${ }^{36}$ Nama lengkapnya adalah Umar ibn Khattab ibn Nufail ibn Abdil Uzza ibn Ribaah ibn Qarth ibn Razaah ibn Ady bin $\mathrm{Ka}^{\prime} \mathrm{b}^{37}$

\section{Terminasi Khalid Bin Walid}

Pada masa Khalifah Abu Bakr, Khalid terlibat dalam melawan orang-orang murtad di bawah panji Abu Bakr, mulai dari gerakan Khalid bin Walid menumpas Nabi Palsu Musailimah al-Kadzdzab dan peristiwa ini menjadi permulaan pertempuran Khalid dengan orang-orang murtad. ${ }^{38}$ Khalifah Abu Bakar memerintahkan Khalid bin Walid agar segera berangkat bersama-sama pasukannya untuk menuju Syam dan menjadi panglima perang di sana. Khalid pun segera melakukan apa yang diperintahkan Khalifah. Maka, mulailah Khalid melakukan perjalanan historis dengan menembus padang sahara yang sebelumnya belum pernah dia lalui. ${ }^{39}$

Di masa khalifah Abu Bakr, Khalid bin Walid menjadi panglima perang berprestasi di peperangan Syam khususnya di perang Yarmuk. Di masa khalifah Umar bin Khattab

alauddin.ac.id/index.php/rihlah/article/view/41 $\underline{67}$

38. Manshur Abdul Hakim, Khalid bin Walid Panglima yang Tak Terkalahkan. (Jakarta: Pustaka Al-Kautsar, 2014), x-xii.

39. Muh. Anis, "Perkembangan Politik Masa AlKhulafa Al-Rasyidun (Abu Bakar as-Siddiq, Umar Bin Khattab, Usman Bin Affan, Ali Bin Abi Thalib)", Al Qalam: Jurnal Kajian Islam \& Pendidikan vol. 8, no. 1 (2016): 52-72, doi: https://doi.org/10.47435/al-qalam.v8i1.204 
turun kedudukannya penjadi komandan pasukan di perang Damaskus dibawah Abu Ubaidah sebagai pemimpin, Khalid dari timur menyerang Damaskus, lalu Abu Ubaidah menyerang Damaskus dari pintu Al Jabiyah Al-Kabir, dan dari pintu Al-Jabiyah Ash-Shaghir Yazid bin Abu Shofyan menyerang. ${ }^{40}$

Perang terakhir yang diikuti oleh Khalid bin Walid sebagai salah satu komandan pasukan perang setelah jatuhnya Damaskus, Abu Ubaidah memerintahkan Khalid untuk mengajak penduduk Qansarin untuk bertakwa kepada Allah, tetapi tidak bisa dilakukan secara damai prosesnya dan malah menantang untuk berperang, Khalid bin Walid sebagai pihak mendapatkan tugas untuk mengajak justru diajak untuk berperang, maka perang tersebut terjadilah dan akhirnya perang Qansarin dimenangkan oleh Khalid dan diangkat sebagai wali kota Qansarin dan memiliki tugas mengawasi gerak Romawi di daerah utara. ${ }^{41}$

Khalid membantu Abu Ubaidah di Hims daerah Syam, akhirnya Muslimin memenangkan Syam bagian utara dan kedaulatan Muslim di Irak dan Syam bisa bertemu. Setelah kedaulatan Islam di Syam aman, Khalid bin Walid membebaskan beberapa daerah di Qilqiah dan Armenia dan mendapatkan harta rampasan yang sangat banyak, Khalid bin Walid memberikan hadiah kepada Asy'as bin Qais. Dari

\footnotetext{
40. Hakim, Khalid bin Walid, 538.

41. Ibid., 551.

42. Haekal, Umar bin Khattab. 229-311.

43. Yat Rospia Brata, Rina Dwi Gustina, "Peranan Abu Ubaidah Bin Jarrah Dalam Perang Yarmuk Tahun 636 M", Jurnal Artefak vol. 2, no. 1 (2019): 45-58,

https://jurnal.unigal.ac.id/index.php/artefak/arti cle/view/303
}

peristiwa Khalid memberikan hadiah menjadi alasan diterminasi oleh Umar bin Khattab secara total dalam dinas kemiliteran. ${ }^{42}$

Menurut Ahmad dalam Brata, ${ }^{43}$ Khalid bin Walid di Madinah menerima dengan lapang dada dan penuh kerelaan padahal saat itu ia sedang dalam puncak kegemilangan. Diperkuat Haekal, ${ }^{44}$ sikap Khalid menerima terminasinya, bahkan terdapat pihak-pihak yang memanas-manasi Khalid untuk memberontak kepada Umar dikarenakan terminasinya yang tidak pantas, tetapi Khalid menentang ide memberontak dan menerima terminasinya dalam dinas kemiliteran oleh Umar bin Khattab.

Untuk memahami posisi Umar dan pandangnya terhadap Khalid sebagai panglima perang dan komando. Pandangan Umar terhadap Khalid sebelum menjabat sebagai Khalifah, Umar menjadi wazir (kak tangan/orang kepercayaan) bagi Abu Bakr. ${ }^{45}$ Mengutip Haekal, ${ }^{46}$ dalam peristiwa Khalid membunuh Malik bin Nuwairah, yang saat itu masih belum jelas kemurtadannya dan setelah itu mengawini istrinya Laila, Umar berpendapat bahwa Khalid tergesa-gesa dan Abu Bakr berpendapat bahwa Khalid meleset saja dalam perhitungan, sehingga tidak akan "menyarungkan" pedang Allah. Tetapi pendapat lain mengatakan dalam Khalid menikahi Laila menurut Argoun, ${ }^{47}$ bahwa pernikahan dengan Laila, sudah

44. Haekal, Umar bin Khattab, 320.

45. Uup Gufron, "Etika Birokrasi Al-Ghazali", Saintifika Islamica: Jurnal Kajian Keislaman vol. 4 no 2 (Des 2017): 221-246, http://jurnal.uinbanten.ac.id/index.php/saintifik aislamica/article/view/1208

46. Haekal, Umar bin Khattab, 69-70.

47. Ibid., 259-260. 
melewati masa iddah tiga kali sesuai dengan kebiasaan saat itu, dikarenakan Malik bin Nuwairah yang telah murtad maka Laila sudah diceraikan tetapi ditawan saat itu, dan Khalid menikahi agar Laila yang sudah ditinggal suaminya tetap pada iman Islam.

Abu Bakar menerima alasan Khalid untuk membunuh Malik bin Nuwairah, dikarenakan disatu sisi Umat Islam membutuhkan kejeniusan Khalid dalam perang, yang membutuhkan kecepatan dalam mengambil keputusan, dan disatu sisi Umar bin Khattab melihat bahwa tidak ada yang boleh keluar dari disiplin administrasi pemerintahan, yaitu dalam pengambilan keputusan yaitu salah satunya pembunuhan Malik bin Nuwairah yang sifatnya masih belum terang, harus dikonsultasikan dengan Khalifah.

Dari realitas diatas yang diungkapkan oleh Haekal, Umar dalam menyarankan terminasi Khalid sudah berjalan sejak zaman Abu Bakr menjadi Khalifah dan Umar menjadi wazir Abu Bakr, dan sekalipun akhirnya Abu Bakr tidak memecat Khalid dalam dinas kemiliteran, Umar menyarankan untuk Khalid dihukum dan ditegur atas kesalahankesalahannya.

Saat Umar menjabat sebagai Khalifah, Umar sudah memiliki pandangan dan pendirian terhadap Khalid, yaitu Khalid sebagai SDM tergesa-gesa dalam mengambil keputusan yang harusnya.

Ketika Umar ketika menjadi Khalifah pengganti Abu Bakr, memberhentikan Khalid sebagai panglima perang di Syam dan mengangkat Abu Ubaidah sebagai Panglima

\footnotetext{
48. Ibid., 97.

49. Argoun, Khalid Bin Walid, 485.

50. Ibid., 575.
}

serta menjadikan Khalid bin Walid dibawah perintah Abu Ubaidah. ${ }^{48}$ Diperkuat Argoun, ${ }^{49}$ dalam Umar mengangkat Abu Ubaidah sebagai panglima pasukan Khalid.

Umar menjabat sebagai Khalifah, membuat aturan sistem baru dalam keuangan tiap wali kota bahwa mereka tidak diperbolehkan untuk memberikan apapun kepada orang lain kecuali atas izin Amirul mukminin. ${ }^{50}$ Sesuai dengan pertimbangan ini nantinya, yang akan memperkuat pendasaran Umar di dalam menterminasi Khalid bin Walid dalam dinas kemiliteran.

Proses terminasi Khalid dimulai dari pemberian surat yang diberikan Umar kepada Abu Ubaidah mengutip Haekal,, ${ }^{51}$ untuk menginterogasi Khalid bin Walid dan mengikatnya dengan serban dan melepaskan topi kebesarannya sampai terungkap dari mana harta yang diberikan kepada Asy'as bin Qais dari harta pribadinya atau dari rampasan perang, dan berisi juga tentang pemecatan Khalid dari dinas kemililiteran.

Mengutip Haekal, ${ }^{52}$ Abu Ubaidah tidak menyampaikan pemecatan secara total dari dinas militer kepada Khalid dalam proses interogasi yang dilakukan oleh Bilal. Akhirnya, Umar mengirim surat langsung kepada Khalid untuk ke Madinah, untuk disampaikan pemberhentian total dari dinas milter yang tidak disampaikan oleh Abu Ubaidah sebelumnya. ${ }^{53}$

Terdapat orang-orang fanatik terhadap Khalid yang menggagap sikap Umar kepada Khalid, keputusan terminasi Khalid berlebihan dan Khalid mengatakan kepada

\footnotetext{
51. Haekal, Umar bin Khattab, 311-315.

52. Ibid.

53. Ibid., 315-317.
} 
Umar bahwa sikap terhadap dirinya tidak pantas. Umar menjawab bahwa Khalid bagi Umar sangat mulia, dicintai di mata Umar, dan nanti Khalid tidak akan menyalahkan Umar lagi terhadap sikapnya dalam terminasi diri Khalid. ${ }^{54}$

Apakah Umar dalam pemberhentian Khalid dalam dinas kemiliteran terdapat motif pribadi? Dikarenakan Umar Ketika menjadi wazir Abu Bakr pernah menyarankan Khalid untuk dipecat, atau masih ada dendam pribadi dikarenakan peristiwa Khalid yang menyerang penyerbuan dengan pasukan berkuda di perang Uhud yang berhasil memojokkan pasukan muslimin. Ini perlu dibuka, sebagai analisis kritis mengenai motif pemberhentian Khalid, dengan demikian kita bisa memahami dengan utuh proses terminasi dan alasan pemberhentian yang disampaikan dalam manajemen terminasi bisa diterima oleh Khalid sebagai pihak yang diberhentikan. Pendapat AshShalabi, ${ }^{55}$ cara pandang melihat pemberian hadiah kepada Asy'as bin Qais ada perbedaan antara Umar dan Khalid, Umar berpendapat fase memikat hati dan memotivasi dengan harta orang yang lemah iman sudah lewat, harta lebih difokuskan pada Muhajirin yang membutuhkan, sedangkan Khalid berpendapat orang-orang mujahid bersama dirinya, lemah imannya sehingga butuh yang mendorong tekad dan semangat mereka untuk berperang di jalan Allah.
Umar saat peristiwa mengatakan tidak memecat Khalid karena benci atau penghianatan, melainkan takut Umat Islam akan terlena mengandalkan Khalid, bukan Allah Swt. Dan Khalid terkena fitnah, menjadi pendasaran bahwa pemecatan tersebut bukan karena prasangka buruk atau dengki dengan Khalid, seperti yang diungkapkan al-Aqqad dalam Argoun. ${ }^{56}$

Mengutip Abdul Hakim, ${ }^{57}$ memberikan hadiah kepada Asy'as bin Qais yang tidak berkonsultasikan dengan Amirul mukminin, serta adanya potensi Umat Islam akan terlena mengandalkan Khalid, bukan Allah Swt. Menjadi pendasaran pemberhentian total Khalid dari dinas kemiliteran.

\section{Manajemen Terminasi Khalid Bin Walid Oleh Umar Bin Khattab}

Dalam kepemimpinan Khalifah Umar Bin Khattab melakukan manajemen terminasi dalam peristiwa pemberhentian Khalid bin Walid, yang merupakan panglima Islam Khalid yang baru masuk Islam saat pasca perjanjian Hudaibiyah antara pihak Nabi dan kafir Quraisy, ${ }^{58}$ dan Khalid menerima hasi terminasi tersebut. Menurut Ash-Shalabi, ${ }^{59}$ seseorang menghampiri Khalid pasca pemberhentian total dari dinas militer di dan mengatakan bahwa pemberhentian Khalid adalah ujian, dan saat itu Khalid mengatakan bahwa ini bukanlah ujian, yaitu ujian yang harus diterima oleh seorang muslim dan meratapinya, di sini terlihat bahwa sikap Khalid bukan panglima yang membangun

58. M. Hamdan Basyar, "Etika Perang Dalam Islam dan Teori Just War" Penelitian Politik vol. 17, no. $1 \quad$ (2020): 17-30 http://ejournal.politik.lipi.go.id/index.php/ipp/a rticle/view/854/554

59. Ash-Shalaby, Biografi Umar bin Khattab, 402. 
"pelaminan agung" diatas merebaknya fitnah dan kemewahan yang merusak melainkan panglima yang membangun kebesaran Islam berdasarkan Iman kepada Allah Swt. Dan menunjukkan iman yang orang-orang pilihan dari sahabat-sahabat khusus Nabi.

Dan diperkuat oleh Haekal, ${ }^{60}$ sikap Khalid menerima terminasinya, bahkan terdapat pihak-pihak yang memanas-manasi Khalid untuk memberontak kepada Umar dikarenakan terminasinya yang tidak pantas, tetapi Khalid menentang ide memberontak dan menerima terminasinya dalam dinas kemiliteran oleh Umar bin Khattab. Proses manajemen terminasinya sebagai berikut:

\section{Tahapan sebelum terminasi}

Tahapan ini memiliki tujuan banyak opsi yang memungkinkan dalam melakukan terminasi, agar bisa menghindari konflik dalam proses terminasi, mengembangkan temu duga/tanya jawab terminasi secara padat, dan meminimalisir dampak terminasi bagi organisasi, dan Umar bin Khattab melakukan tahapan ini sebagai berikut:

Setelah keputusan untuk menterminasi dibuat, diskusi dengan sahabat lainnya untuk pemberhentian SDM diadakan untuk mengembangkan pedoman khusus tentang bagaimana melakukan temu duga/tanya jawab pemutusan kerja SDM untuk menyampaikan perihal pemberhentian kepada SDM ${ }^{61}$ Umar tidak melakukan diskusi dengan para sahabat untuk menemukan metode temu duga/tanya jawab yang tepat untuk menyampaikan pemberhentian kepada SDM, tetapi Umar bin Khattab sudah menyusun metode terminasi secara total dari Khalid dari dinas kemiliteran, yaitu metode interogasi yang dituliskan dalam surat yang ditujukan kepada Abu Ubaidah dan menjadikan Abu Ubaidah menyampaikan perihal interogasi dan penyampaian pemberhentian total Khalid dari dinas kemiliteran. Dengan demikian Umar tidak melakukan diskusi dengan para sahabat terlebih dahulu mengenai opsi-opsi pedoman pemberhentian total Khalid dari dinas kemiliteran saat itu, dan langsung diputuskan opsi pedoman pemberhentian Khalid seperti yang di sampaikan dalam surat kepada Abu Ubaidah.

\section{Tahapan saat terminasi}

Manajemen saat terminasi yang dilakukan oleh Umar bin Khattab kepada Khalid bin Walid, dibawah ini diuraikan mengenai pendekatan yang dibuat oleh Umar dalam menterminasi Khalid dalam dinas kemiliterannya secara total, yaitu pendekatannya logis dan sensitif, singkat, manusiawi, dan final, sebagai berikut:

"Siapa" yang akan menyampaikan, bisa seseorang yang dianggap senior atau dihormati untuk menyampaikan terminasi tersebut, ${ }^{62}$ Dengan disampaikannya perihal terminasi secara menyeluruh Khalid bin Walid dari dinas kemiliteran oleh Umar bin Khattab, Umar bin Khattab sendiri merupakan Khalifah pemimpin tertinggi Umat Islam yang dipilih oleh Abu Bakr, ${ }^{63}$ Umar sendiri dihormati dalam kalangan Umat Islam. Umar sendiri merupakan sahabat Nabi yang ikut dalam semua perang bersama Nabi dan merupakan penasehat

\footnotetext{
62. Ibid., 15.

63. Haekal, Umar bin Khattab, 79.

60. Haekal, Umar bin Khattab, 320.

61. Finnie, dkk, Good Endings, 13.
} 
Nabi, ${ }^{64}$ dibandingkan dengan Khalid yang baru masuk Islam saat pasca perjanjian Hudaibiyah antara pihak Nabi dan kafir Quraisy, ${ }^{65}$ meskipun demikian dan menurut Thabari dalam Argoun, ${ }^{66}$ menurut Abu Bakr bahwa Khalid dan Umar setara dalam memimpin pasukan perang.

Dengan adanya kedudukan masing-masing antara Umar dan Khalid, ketika Umar menyampaikan perihal pemberhentian Khalid dalam dinas kemiliteran, Khalid yang pada waktu itu menyampaikan keluhannya kepada Umar mengenai pemberhentian dirinya dan segala macam prosesnya, bisa menerima apa yang disampaikan oleh Umar, dikarenakan melihat kedudukan Umar sebagai pemimpin tertinggi Umat Islam, dan dengan keimanannya Khalid tidak melakukan pemberontakan kepada pemimpin tertinggi Umat Islam atas pemberhentian dirinya. Juga kesetaraan dalam memberikan strategi perang, pengambilan kebijakan ini untuk kejayaan Umat Islam, dikarenakan adanya potensi fitnah terhadap Khalid dan lunturnya akidah umat Islam.

Dengan demikian, Khalid bisa menahan kemarahannya dan menerima keputusan sebagai muslim yang baik dan taat terhadap keputusan terminasi dan tidak akan melakukan pemberontakan.

64. Fitmawati, “Manajemen Baitul Mal Pada Masa Khalifah Umar bin Khattab R.A: Sebuah Tinjauan Sejarah", Jurnal IImiah Syi'ar: Kajian Dakwah Dan Wacana Islam vol. 19, no. 1 (2019): 1-29, https://ejournal.iainbengkulu.ac.id/index.php/sy iar/article/view/2262

65. M. Hamdan Basyar, "Etika Perang": 17-30, http://ejournal.politik.lipi.go.id/index.php/ipp/a rticle/view/854/554
"Apa" kata-kata yang disampaikan kepada SDM perang yang akan dipecat harus menunjukkan rasa hormat, bisa juga dengan bahasa non-verbal menunjukkan rasa hormat tersebut, ${ }^{67}$ saat Umar memberikan pemberitahuan bahwa Khalid dipecat, Umar mengundang sendiri Khalid untuk memberitahukan terminasinya di Madinah, menunjukkan sikap hormat kepada Khalid dengan memberitahuan secara langsung dan menayakan asal hadiah yang diberikan Khalid kepada Asy'as bin Qais, dan apapun jawabannya baik berasal dari hartanya ataupun rampasan perang yang menjadi alasan Khalid. ${ }^{68}$ Serta Umar menyampaikan bahwa terminasi Khalid untuk kebaikan Khalid dan mengungkapkan bahwa Khalid dalam pandangan Umar adalah orang yang mulia dan dicintai. ${ }^{69}$ Dengan begitu, Khalid bisa menahan amarah terhadap terminasinya dan tidak memberontak kepada Umar. $^{70}$ Dengan penyampaian alasan pemberhentian Khalid kepada Khalid secara verbal bukan karena benci dan disertai ungkapan dengan rasa kagum Umar kepada Khalid, menunjukkan rasa hormat Umar kepada Khalid selama proses penyampaian terminasi kepada Khalid. Dengan demikian Khalid merasa dihormati.

"Kapan" waktu yang tepat untuk menyampaikan pesan terminasi tersebut, dimana situasi yang bisa diterima dan momen yang tepat dalam pencapaian tujuan organisasi, adanya momen kesalahan Khalid

\footnotetext{
66. Argoun, Khalid Bin Walid, 488.

67. Finnie, dkk, Good Endings, 16.

68. Hakim, "Khalid bin Walid Panglima Yang Tak Terkalahkan", 578

69. Haekal, Umar bin Khattab, 319-320.

70. Ibid.
} 
oleh Umar dalam pemberian hadiah, kuatnya serta kedudukan Umat Islam terhadap Persia dan Romawi. ${ }^{71}$ Diperkuatnya momen tumbuhnya potensi fitnah terhadap Khalid dan meningkatnya rasa kagum umat Islam terhadap kepemimpinan Khalid sebagai SDM perang, Jika Khalid masih menjadi SDM, berpotensi menggeser akidah umat Islam yaitu tiada kemenangan tanpa Khalid. Padahal Umar berpendapat bahwa kemenangan dari Allah, dan siapapun yang memperjuangkannya, bukan hanya karena ada Khalid semata. Umar ingin menyelamatkan akidah umat Islam. Maka terminasi Khalid dari dinas kemiliteran total disampaikan.

"Dimana" tempat penyampaian pesan/hasil keputusan terminasi tersebut, bisa ditempat netral atau tempat yang mendukung penyampaian pesan/hasil keputusan, ${ }^{72}$ terminasi Khalid secara total dari dinas kemiliteran disampaikan di Medinah, yang dianggap tempat yang netral ataupun tidak memiliki potensi untuk terjadi gejolak ketika info pemberitahuan diberikan kepada Khalid, ataupun terdapat gejolak tetapi jauh dari bekas pasukannya di Qanssirin, sehingga potensi masih bisa diredam dan faktanya Khalid menerima dengan lapang dada terminasi dirinya ketika info pemberhetian dirinya disampaikan di Madinah, bahkan tidak mau diajak untuk melakukan pemberontakan kepada Umar atas terminasi dirinya.

"Mengapa" pekerja tersebut diterminasi, yaitu berupa alasan yang terbaik bagi Khalifah dan SDM itu sendiri dalam pesan/hasil keputusan terminasi dirinya, ${ }^{73}$

\footnotetext{
71. Haekal, Umar bin Khattab, 229-313

72. Finnie, dkk, Good Endings, 16.

73. Ibid.
}

dalam terminasi Khalid, Umar menyampaikan alasan mengapa Khalid diterminasi, yaitu dikarenakan kesalahan dalam pemborosan harta ghanimah yang sudah didapatkan, dan tanpa berkonsultasi kepada Umar mengenai penggunaan harta ghanimah tersebut, padahal sudah ada kebijakan bahwa setiap wali/SDM Umar harus berkonsultasi dalam penggunaan harta. Disatu sisi sesuai pendapat Haekal, ${ }^{74}$ ketakutan Umar bahwa banyak orang akan terpesona terhadap Khalid dan hanya mau berkorban untuk Khalid, bukan kepada Allah. Secara tidak langsung Umar menampakkan watak keras kepada Khalid, menunjukkan benturan watak keras antara Khalid dengan Umar dan perbedaan pandangan dalam kehidupan pemerintahan, serta juga memiliki kesetaraan kecerdasan dalam strategi perang, sehingga berpotensi saling berbenturan hebat dan terlihat dari kasus sebelumnya dalam peristiwa Malik bin Nuwairah, dan puncaknya pengelolaan ghanimah oleh Khalid yang memiliki pandangan berbeda, dan mengharuskan salah satu mengalah demi kepentingan strategi militer yang komperhensif serta kemaslahatan umat.

"Bagaimana" pesan tersebut disampaikan, yaitu dengan sikap dari Khalifah yang positif, menenangkan, dan tegas agar situasi bisa sesuai dengan harapan, dan ditunjukkan pertimbangan dan perhatian, tetapi pastikan finalitas pesan/hasil keputusan terminasi tersebut jelas. $^{75}$ Umar menyampaikan terminasi di Madinah merupakan keputusan yang final, dan menyampaikan bahwa terminasi tersebut bukan dikarenakan nafsu pribadi, tetapi dikarenakan atas rasa cinta

\footnotetext{
74. Haekal, Umar bin Khattab, 320.

75. Ibid.
} 
serta menghormati Khalid, sehingga Khalid yang awalnya menyalahkan Umar menjadi tenang dan menerima terminasi atas dirinya. ${ }^{76}$ Dengan demikian, Umar sebagai Khalifah menyampaikan sendiri perihal terminasi kepada Khalid, dengan menunjukkan bahwa keputusan ini sudah final Khalid tidak diangkat dalam jabatan apapun yang menandakan diberhentikan total dari dinas kemiliteran, dan menunjukkan sikap positif bahwa apa yang dilakukan didasari rasa cinta serta menghormati Khalid.

\section{Kesimpulan}

Dalam proses terminasi Khalid bin Walid, Umar bin Khattab melakukan manajemen terminasi dengan: (1) Tahapan sebelum terminasi. Mengembangkan pedoman khusus tentang melakukan temu duga/tanya jawab pemutusan hubungan kerja terhadap Khalid bin Walid yang dituliskan dalam surat yang ditujukan kepada Abu Ubaidah dan pendasaran menterminasi Khalid tidak lepas dari kriteria yang sudah dibuat oleh Umar ketika menjabat sebagai Khalifah mengenai standar wali kota, yaitu keuangan tiap wali kota bahwa mereka tidak diperbolehkan untuk memberikan apapun kepada orang lain kecuali atas izin Umar sebagai Khalifah, sehingga menjadi pendasaran dalam terminasi Khalid ketika Khalid melanggar ketetapan keuangan dengan memberikan hadiah uang kepada Asy'as bin Qais.

(2) Tahapan saat terminasi. Umar melakukan terminasi mempertimbangkan: Penyampai terminasi adalah Khalifah Umar sendiri dikarenakan kedudukan Khalifah yang dihormati; (b) Hal yang disampaikan adalah keputusan terminasi atas Khalid dan penyebab diterminasinya Khalid karena tidak sesuai dengan kebijakan Khalifah; (c) Momen yang tepat dalam melakukan terminasi ketika Khalid melakukan kesalahan dalam perihal keuangan yang tergesa-gesa dan sudah kuatnya kedudukan Islam di Syam dan Persia sudah kuat; (d) Tempat yang netral yang bisa meredam gejolak dari terminasi yaitu di Madinah sebagai tempat yang netral dimana tempat yang tidak dominan pendukung dari Khalid; (e) Alasan yang logis dan bisa diterima dalam terminasi, yaitu kesalahan dalam pemborosan harta ghanimah dan bertentangan dengan ketetapan penggunaan keuangan hasil ghanimah; (d) Pesan terminasi disampaikan dengan baik, yaitu Umar mampu menenangkan Khalid sebagai pihak yang terterminasi dan Khalid menerima secara final terminasi atas dirinya dengan menujukkan sikap positif terhadap Umar.

Adanya pembahasan ini, bisa menjadi hikmah bagi organisasi dakwah khususnya manajer sumber daya manusia, melakukan manajemen terminasi bisa berjalan dengan baik, yaitu setelah keputusan terminasi terhadap SDM sudah diambil, maka dilakukan manajemen terminasi mulai dari tahapan sebelum terminasi dengan: tahapan saat terminasi dilakukan organisasi dakwah khususnya manajer sumber daya manusia adalah standar dalam mengkomunikasikan terminasi tersebut bisa direncanakan terlebih dahulu, agar terminasi tersebut bisa memenuhi kelogisan diterima oleh SDM yang di terminasi, sensitifitas tidak terlalu tinggi sehingga SDM bisa menerima dengan lapang dada, singkat

76. Ibid., 319-320. 
dalam penyampaian sehingga SDM memahami inti terminasi kepada dirinya, manusiawi dalam proses penyampaian sehingga SDM merasa di hormati dengan jasa-jasanya selama ini, dan final bagi pekerja tersebut sehingga SDM memiliki kejelasan mengenai nasibnya di organisasi dan bisa move on. Merencanakan penyampaian terminasi mulai dari siapa, apa, kapan, dimana, mengapa dan bagaimana.

Sehingga, dengan melakukan tahapan terminasi, maka tujuan terminasi dan tidak menyebabkan gejolak yang berlarut-larut yang menyebabkan kerugian tenaga, waktu, pikiran dan materi, dan terhambatnya pencapaian tujuan organisasi.

\section{Bibliografi}

Ahmad Zaini, "Pengaturan Pemutusan Hubungan Kerja (PHK) Menurut Peraturan Perundanganundangan Ketenagakerjaan", Al-Ahkam vol. 13, no. 1 (Juni 2017): 76-110. doi: http://dx.doi.org/10.37035/ajh.v13i1.1753.

Al-Bukharyal-Ja'fi, Muhammad bin Ismail Abu Abdillah. al-Jami al-Shahih al-Muhtashar, Jilid I. Beirut: Dar ibn Katsir, 1987/1407.

Alfa, Mawey Z. Sri Murni, Ferdy Roring, "Faktor-faktor yang mempengaruhi Pemutusan Hubungan Kerja Karyawan Pada PT. PLN (Persero) Rayon Manado Utara", Jurnal EMBA vol. 4, no. 1 (Maret 2016): 261-271. doi: https://doi.org/10.35794/emba.v4i1.11594

Almasri, M. Nazari. "Manajemen Sumber Daya Manusia: Implimentasi Dalam Pendidikan Islam". Kutubkhanah: Jurnal Penelitian Sosial Keagamaan vol. 19, no. 2 (Jul-Des 2016): 133-150. http://ejournal.uin-suska.ac.id/index.php/Kutubkhanah/article/view/2547

Anis, Muh. "Perkembangan Politik Masa Al-Khulafa Al-Rasyidun (Abu Bakar as-Siddiq, Umar Bin Khattab, Usman Bin Affan, Ali Bin Abi Thalib)". Al Qalam: Jurnal Kajian Islam \& Pendidikan vol. 8, no. 1 (2016): 52-72. doi: https://doi.org/10.47435/al-qalam.v8i1.204

Argoun, Shadiq Ibrahim. Khalid Bin Walid Sang Legenda Militer Islam. Tinta Medina: Solo, 2015. Ash-Shalaby, Ali Muhammad, Biografi Umar bin Khattab. Jakarta: Yayasan Ash-Shilah, 2014.

Athamina, Khalil. The Appointment and Dismissal of Khalid B. Al Walid Form the Supreme Command A Study of The Political Strategy of The Early Muslim Caliphs in Syria, Arabica E.J Brill Leiden Tome XLI (1994): 253-272. doi: https://doi.org/10.1163/157005894X00191

Basyar, M. Hamdan Basyar. "Etika Perang Dalam Islam dan Teori Just War". Jurnal Penelitian $\begin{array}{llllll}\text { Politik vol. } 17, \quad \text { no. } & 1 & \text { (2020): } & \text { 17-30. }\end{array}$ http://ejournal.politik.lipi.go.id/index.php/ipp/article/view/854/554

Brata, Yat Rospia. Rina Dwi Gustina. "Peranan Abu Ubaidah Bin Jarrah Dalam Perang Yarmuk Tahun 636 M". Jurnal Artefak vol. 2, no. 1 (2019): 45-58. https://jurnal.unigal.ac.id/index.php/artefak/article/view/303

Buwana, Sudibyo Aji Narendra, Mario Septian Adi Putra. "Implimentasi Pemutusan Hubungan Kerja (PHK) Terhadap Pekerja Status Perjanjian Kerja Waktu Tertentu (PKWT) Pada PT X Kota Malang". Jurnal Studi Manajemen vol. 9, no. 2 (Okt 2015): 202-214. https://ecoentrepreneur.trunojoyo.ac.id/kompetensi/article/view/1628 
Dwiyanto, Herly. “Manajemen Sumber Daya Manusia Madani di Universitas Negeri”. Jurnal Prodi $\begin{array}{lllll}\text { Manajemen Pertahanan vol. } 3 \text {, no. } 2 \text { (2017): } & \text { 61-72. }\end{array}$ http://jurnalprodi.idu.ac.id/index.php/MP/article/view/178

Fathammubina, Rohendra. Rani Apriani. "Perlindungan Hukum Terhadap Pemutusan Hubungan Kerja Sepihak bagi Pekerja”. Jurnal IImiah Hukum De'Jure: Kajian Ilmiah Hukum vol. 3, no. 1 (Mei 2018): 108-130. doi: https://doi.org/10.35706/dejure.v3i1.1889

Finnie JR, Robert A. Paul B.Sniffin. Good Endings: Managing Employee Terminations. Washington: College and University Personnel Associations, 1984.

Fitmawati. "Manajemen Baitul Mal Pada Masa Khalifah Umar bin Khattab R.A: Sebuah Tinjauan Sejarah". Jurnal IImiah Syi'ar: Kajian Dakwah Dan Wacana Islam vol. 19, no. 1 (2019): 129. https://ejournal.iainbengkulu.ac.id/index.php/syiar/article/view/2262

Gufron, Uup. "Etika Birokrasi Al-Ghazali". Saintifika Islamica: Jurnal Kajian Keislaman vol. 4, no 2 (Des 2017):

221-246. http://jurnal.uinbanten.ac.id/index.php/saintifikaislamica/article/view/1208

Haekal, Muhammad Husain.Umar bin Khattab, penerjemah: Ali Audah. Jakarta: PT Pustaka Litera antarNusa, 2013.

Hakim, Manshur Abdul. Khalid bin Walid Panglima yang Tak Terkalahkan. Jakarta: Pustaka AlKautsar, 2014.

Harmonika, Sri. "Hadist-hadits tentang Manajemen Sumber Daya Manusia (SDM)". Jurnal AtTadair Prodi MPI STAI Darul Kalam vol. 1, no. 1 (2017):1-14. http://ejournal.kopertais4.or.id/sasambo/index.php/atTadbir/article/view/2990

Husaini. Happy Fitria. "Manajemen Kepemimpinan Pada Lembaga Pendidikan Islam". Jurnal Manajemen, Kepemimpinan, dan Supervisi Pendidikan vol. 4, no. 1, (Januari-Juni 2019): 43-54. doi: http://dx.doi.org/10.31851/jmksp.v4i1.2474

Huzair Zainal, "Kisruh Lebaran Lebih Awal, Imam Masjid Dipecat”, Okenews.com, 2 September 2011, diakses pada 9 2020, https://news.okezone.com/read/2011/09/02/340/498279/kisruh-lebaran-lebih-awalimam-masjid-dipecat

Ilyas, Rahmat. "Manusia sebagai Khalifah dalam perfektif Islam". Mawa izh vol. 1, no. 7 (Juni 2016): 169-195. doi: https://doi.org/10.32923/maw.v7i1.610

Intan, Salmah. "Kekhalifaan Umar Ibn Khattab (13-23 H/ 634-644 M)". Rihlah: Jurnal Sejarah dan Kebudayaan vol. 5, no. 2 (2017): 137-151. http://journal.uinalauddin.ac.id/index.php/rihlah/article/view/4167

Junaidy, Abdul Basith. "Perang yang benar dalam Islam". Al-Daulah: Jurnal Hukum dan Perundangan Islam vol. 8, no. 2 (Oktober 2018): 486-512. doi: https://doi.org/10.15642/ad.2018.8.2.486-512

Maringka, Inggrit Natalia. Lotje Kawet, Irvan Trang, “Hubungan Lingkungan kerja dan kompensasi terhadap kinerja karyawan pada PT. Bank SULUTGO Cabang Utama Manado". Jurnal EMBA vol. 5, No. 2 (Juni 2017):2251-2259. doi: https://doi.org/10.35794/emba.v5i2.16653

Miranti, Agni. Yuana Tri Utomo, dan Wijiharta. "Peran Umar Bin Khattab dalam Manajemen Konflik". AT-TAUZI': Jurnal Ekonomi Islam vol. 16, no. 1 (2017), 95 - 109. http://jurnalhamfara.ac.id/index.php/attauzi/article/view/28 
Muslim, Muh. "Dilema Pemutusan Hubungan Kerja Bagi Karyawan". ESENSI: Jurnal Manajemen Bisnis vol. 18, no. 3 (2015): 100-110. journal.id/index.php/ESENSI/article/view/100

Nawawi, Ismail. Metode Penelitian Kualitatif. Jakarta: Dwiputra Pustaka Jaya, 2012.

Nuroini, Indi. "Penerapan Perjanjian Bersama Dalam Pemutusan Hubungan Kerja". Jurnal Yudisial vol. 8, no. 3 (2015): 319-338. doi: http://dx.doi.org/10.29123/iy.v8i3.61

Prameswari, Karina. Emi Puasa Handayani. "Pengaturan Pemutusan Hubungan Kerja Antara Karyawan Dengan Perusahaan”. Mizan: Jurnal IImu Hukum vol. 8, no. 1 (Juni 2018): 99112. https://ejournal.uniska-kediri.ac.id/index.php/Mizan/article/view/923/734

Pratama, M. Al Qautsar. Budi Sujati. "Kepemimpinan dan Konsep Ketatanegaraan Umar Ibn AlKhattab". JUSPI: Jurnal Sejarah Peradaban Islam vol. 2, no. 1 (2018): 59-70. doi: http://dx.doi.org/10.30829/i.v2i1.1496

Sonhaji. "Analisis Yuridis Pemutusan Hubungan Kerja Akibat Kesalahan Berat Pekerja". Administrative Law \& Governance Journal vol. 2, no.1 (Maret 2019): 60-78. doi: https://doi.org/10.14710/alj.v2i1.60-78

Swasto, Bambang. Manajemen Sumber Daya Manusia. Malang: UB Press, 2011

Widayanti. "Tinjauan Pelaksanaan Pemutusan Hubungan Kerja (PHK) Berdasarkan Undangundang Nomor 13 Tahun 2003 Tentang Ketenagakerjaan". Hukum dan Dinamika Masyarakat vol. 15, no. 2 (April 2018): 168-176. doi: http://dx.doi.org/10.36356/hdm.v15i2.686

Winarti. Endah. "Perencanaan Manajemen Sumber Daya Manusia Lembaga Pendidikan". Jurnal $\begin{array}{llllll}\text { Tarbiyatuna vol. } \quad 3, & \text { no. } & 1 & \text { (2018): } & \text { 1-26. }\end{array}$ http://ejournal.kopertais4.or.id/mataraman/index.php/tarbiyatuna/article/download/34 $\underline{34 / 2577 /}$ 
Andi Susanto 